\title{
The Adoption of IS/IT Investment Evaluation and Benefits Realization Methodologies in Service Organizations: IT Maturity Paths and Framework
}

\author{
Chad Lin \\ Curtin University of Technology \\ E-Mail: elin123au@yahoo.com.au \\ Yu-An Huang \\ National Chi Nan University \\ E-Mail: yahuang788@gmail.com \\ Man-Shin Cheng \\ National Formosa University \\ E-Mail: mscheng@sunws.nfu.edu.tw
}

\begin{abstract}
This research examines the relationship between the levels of IT maturity and the use of IS/IT investment evaluation and benefits realization methodologies via case studies and survey in the service sector. The findings indicate that IT maturity has a positive impact on the adoption of IS/IT investment evaluation and benefits realization approaches. A major contribution of this research is the development of an IS/IT maturity, investment evaluation and benefit realization methodologies matrix via the case studies. The matrix can assist service organizations in making and substantiating better business decisions. The relationship between the level of IT maturity and the use of IS/IT investment evaluation and benefit realization methods has been further tested and validated in the subsequent survey.
\end{abstract}

Keywords: IS/IT Investment Evaluation, IT Maturity, Benefits Realization, Service Sector 


\section{INTRODUCTION}

Research studies have often reported contradictory findings on the effect of information systems/information technology (IS/IT) expenditure on organizational productivity (Farbey et al., 1992; Changchit et al., 1998) and thus, the term "productivity paradox" has gained increasing notoriety as many studies have suggested relatively static productivity and rising IS/IT expenditure (Willcocks and Lester, 1997). The productivity paradox is the notion that despite large investments in IS/IT over many years, it has been difficult to determine where the IS/IT benefits have actually occurred, if indeed there have been any (Willcocks and Lester, 1997). Some studies suggest that IS/IT investment produces negligible benefits (e.g., Strassmann (1997)) while others report a positive relationship between organizations' performance and IS/IT spending (e.g., Lee and Barua (1999)). There are others who argue the confusion was due to the inappropriate or ineffective use of IS/IT evaluation methodologies in most organizations (e.g., Lin et al. (2005)). In particular, little is known about the IS/IT investment evaluation practices in the service organizations (Mohamed and Hussain, 2005; Schultz, 2006). In addition, it is unclear whether the service organizations' ability to evaluate IS/IT investments is determined by their levels of IT maturity.

All IT maturity stage models proposed in the past had provided a set of variables for determining the stage of an organization in terms of its IT maturity (e.g. Nolan (1979)). However, none of these models had studied the relationship between the levels of IT maturity and the use of IS/IT investment evaluation methodologies (IEMs) and IS/IT benefits realization methodologies (BRMs). Therefore, we argue that the degree of adoption of management/business processes such as the use of IEMs and BRMs is likely to be determined or influenced by the level of IT maturity of the organization.

The main objective of this paper is to examine the relationship between the levels of IT maturity and the use of IEMs and BRMs in the service sector. Initially, relevant literature regarding IT maturity will be briefly discussed. Following that, the research approach used will be described. In particular, research findings from the case studies and the survey will be provided. The three phases of analysis in the case study which lead to the development of a maturity matrix will be discussed in some details. It will be argued that the matrix will enable the service organizations to evaluate themselves in terms of their use or non-use of IEMs and BRMs and thus plan towards greater IT maturity. The matrix will be tested and validated via the subsequent survey. 


\section{LITERATURE REVIEW}

\section{IS/IT Investment Evaluation and Benefits Realization}

Globally, it has been estimated that computer and telecommunications investments now amount to half or more of most large organizations' annual capital expenditures (Willcocks and Lester, 1997). Global IS/IT spending, as forecasted by Global Insight, is likely to increase to over US\$3.2 trillion in 2007 (WITSA, 2004). IS/IT spending is very substantial and is increasing in all parts of the world. Therefore, it would seem wise for the service organizations, in particular, to pay particular attention to adopting formal IS/IT investment evaluation and benefits realization methodologies or processes to evaluates their IS/IT investments and to ensure that the expected benefits from these investments are eventually realized (Dibb, 2001; Schultz, 2006).

It is crucial to consider the historical and methodological connection between IS/IT investments evaluation methods (IEMs) and IS/IT benefits realization methods (BRMs). IEMs have been in use at least since Melone and Wharton (1984 in Farbey et al., 1992), while discussion and use of BRMs appears later in the literature (e.g. Ward et al. (1996)). IEMs represent a genre of methodology that is stereotypically concerned with making investment decisions about IT projects. In other words, the domain of concern is more about selecting the project or projects that at the outset seem to offer the greatest returns or benefits for the outlay. Early examples of IEMs emphasize the use of accounting indicators such as payback period, ROI and IRR (e.g. Takatsu (1984)) whereas later IEMs link the decision making process more strategically (Dos Santos, 1994; Love et al., 2005). Some of the formal IEMs published in the literature are: (1) Information Economics approach (Parker et al., 1988); (2) Multi-object, multi-criteria methods (Farbey et al., 1992); and (3) Options theory (Dos Santos, 1994).

However, IEMs alone are insufficient in terms of ensuring that the benefits identified and expected by organizations are realized and delivered (Lin et al., 2005). This is because IEMs only enable or create a capability to derive benefits (Tsao et al., 2004). BRMs also need to be adopted in order to ensure that expected benefits are realized once a decision to invest has been taken (Changchit et al., 1998). This involves planning how and when benefits will be realized and deciding who will be responsible for achieving benefits as well as actually overseeing the realization of benefits (Lin et al., 2005; Ward et al., 1996). Some of the formal BRMs published in the literature are: (1) Cranfield Process Model of Benefits Management (Ward et al., 1996); (2) DMR's 
Benefit Realization Model (Truax, 1997); and (3) Model of Benefits Identification (Changchit et al., 1998).

\section{The Stages of IT Maturity}

As mentioned earlier, discussion in the IS/IT literature has centered mainly on why methodologies for evaluating investments and managing benefits should be implemented but has generally failed to specify when and under what conditions an organization is ready to adopt such methodologies. Before one can determine when and under what conditions such formal methodologies should be implemented by organizations, it is necessary, to look at organizational IT maturity because this is linked with the ability of an organization to adopt and implement methodologies. According to the literature, organizational growth with respect to the use of IS/IT and the approach organizations take in the management and planning of information systems is conceived in terms of clearly defined stages of maturity (Galliers and Sutherland, 1991).

Various stages of growth models have been presented by researchers to describe the evolution of organizational information systems (e.g. Galliers and Sutherland (1991), Nolan (1979)). Despite some criticism of these models, they provide an insightful organizing framework for thinking about IT change in organizations (Galliers and Sutherland, 1991). The Nolan stages of growth model of evolution related to organizational information systems (Nolan, 1979) is probably the most widely known and utilized model of this type. However, the Nolan model has attracted criticisms over the years. Nolan's own elaboration of the model over the years suggests that maturity is not a static concept.

The revised stages of growth model by Galliers and Sutherland (1991) is meant to overcome some of the limitations by introducing a means of bringing together a range of key elements associated with the operation and management of an organization generally. The revised model of Galliers and Sutherland (1991) can be represented as six stages, each with its particular set of conditions associated with the seven "S" elements. The seven elements are strategy, structure, systems, staff, style, skills, and superordinate goals. The six stages of the revised model are: ad hocracy, starting the foundations, centralized dictatorship, democratic dialectic and cooperation, entrepreneurial opportunity, and integrated harmonious relationships. The revised model assessed the organization's ability to obtain business value from IT directly to its level of organizational maturity and the results provided crucial information about the 
organization's ability to effectively utilize IT in order to achieve competitive advantage and business goals. This revised model was chosen as a useful framework to understand these practices. In particular, the seven "S" elements provided a rich set of conditions upon which we could analyze an organization's maturity, and by using these we were able to be confident about our benchmarking of the case study organizations. Unsurprisingly, higher level of IT maturity meant higher degree of organizational ability to address these seven elements.

\section{RESEARCH APPROACH}

The study reported in this paper uses a combination of case study and survey research approaches (a pluralist approach) (Figure 1). According to Mingers (2001), the results will be richer and more reliable if different research methods are combined together. The use of multiple methods (triangulation) such as case study and survey increases the reliability of the data and serves to corroborate the data gathered from other sources (Mingers, 2001).

\section{Stage 1}

In order to examine key issues and perceptions that underpin the IS/IT evaluation practices in the service industry, two in-depth case studies were conducted in two different large service organizations. Case study utilizing semi-structured interviews, observation, and document review were employed for this research, since the need for using multiple sources of data arises from the ethical need to increase the reliability and validity of the research processes (Yin, 2002).

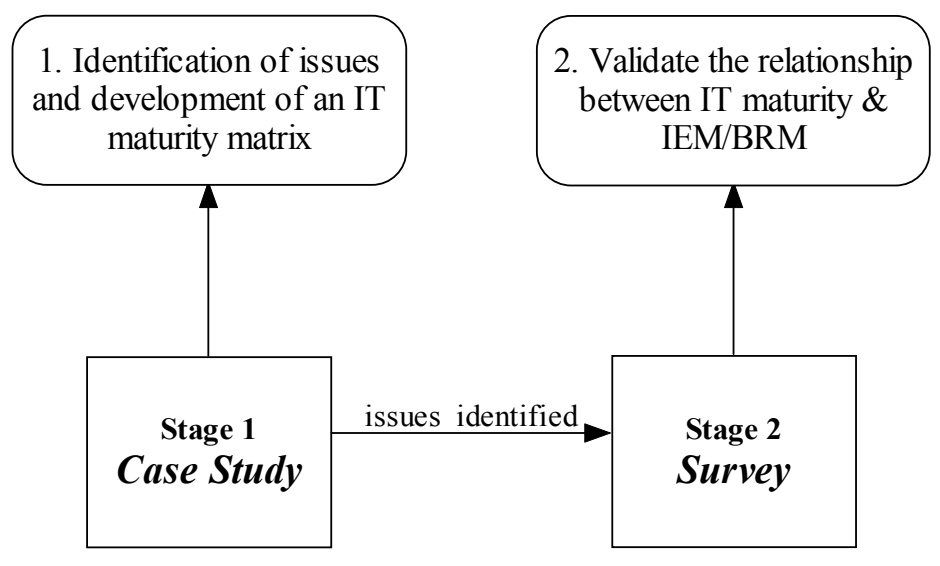

Figure 1 Research design 
Before the case study was conducted, a pilot survey was carried out to first obtain an overview of current Australian service industry practices and norms in managing IS/IT benefits and evaluation. Questionnaires were sent to 100 IT managers in Australian service organizations. The pilot survey results show some similarity to much of the nonAustralian studies (e.g. Ward et al. (1996) and Willcocks and Lester (1997)). In summary, a variety of formal IS/IT investment evaluation processes and techniques were used, costs were of great concern, though formal evaluation itself was not carried out by most organizations. Many respondents considered their financially-based evaluation techniques (such as NPV and ROI) were not perfect, though they did try to incorporate intangible benefits into the process (often without reviewing them in postimplementation, unfortunately). Another key point from the survey results was that while more than two-thirds of the survey respondents indicated that they had ever used an IEM, only about one-third had ever utilized a BRM. This survey had posed an unanswered question - whether or not the variable usage of IEMs and BRMs was caused by the different levels of IT maturity among the responding service organizations?

Then, the case study was carried out with two large Australian service organizations that were involved in major IS/IT projects. The data collection at these two organizations continued until a point of theoretical saturation, which is when the value of an additional interview was considered to be negligible (Eisenhardt, 1989). In total, twenty in-depth interviews were conducted with eleven key participants from these two organizations and seven key participant from their four major external IS/IT project contractors. The interviewees were from different levels of management and therefore, should provide different perspectives. Each interview lasted around two hours. The questions asked during the interview were related to the organizations' five major IS/IT project contracts, the contractual relationship between the organizations and the contractors, IS/IT investment evaluation and benefits realization processes used, and IT maturity of the organizations.

The interviews were recorded and transcribed in order to acquire a full description of the interviewee's comments, yielding 250 pages of transcripts. In addition to the use of the semi-structured interviews and observation data collection techniques, the researcher examined more than 1000 pages of relevant documents (e.g. annual reports) that were collected from the participating organizations. These documents provided some useful means of corroborating data from the other sources. The qualitative content analysis was 
then used to analyze the qualitative data (Miles and Huberman, 1994). Where there were discrepancies in the interpretation of responses to the questions these were resolved by consultation between the researchers and in some cases further explanation from the interviewees. The case study results will be further elaborated later.

\section{Stage 2}

In the second stage, questionnaires were sent to IT managers/CIOs of top 800 Australian service organizations randomly selected from the Dun and Bradstreet company list. The survey was conducted to investigate many aspects of IS/IT investment evaluation and benefit management processes and practices in large Australian organizations. In total, 141 responses were received, representing a response rate of $17.6 \%$. This response rate was comparable to many other similar survey studies conducted in the last few years:

$10.8 \%$ by Laitinen (2002) in his study of performance measures in small Finnish technology companies; and

$10 \%$ by Wang (2002) in his study of customized software outsourcing from a group of medium to large-sized firms in Taiwan.

In addition, late returns were compared with other response received earlier in order to check for non-response bias. No significant differences were detected between two samples. Respondents were asked to indicate their agreement on a 6-point scale ( 1 for strongly disagree and 6 for strongly agree) with statements concerning five main constructs: (1) IT maturity; (2) IS/IT investment evaluation methodology; and (3) IS/IT benefits realization methodology.

The IT maturity scale was based on Galliers and Sutherland's Revised Stages of Growth Model (Galliers and Sutherland, 1991). The scale was revised into a seven-item measurement and the alpha value for this scale was 0.88 , indicating acceptable values of internal consistency (Nunnally, 1978). On the other hand, the IS/IT investment evaluation and benefits realization methodologies scales were derived from Ward et al. (1996). The scale measured the levels of usage for IS/IT investment evaluation and IS/IT benefits realization methodologies by responding organizations. Each scale has three items and alpha values for these two scales are 0.86 and 0.87 , respectively. Both scales measured the usage, wide use, and effective use of the methodologies. 
Table 1 Correlation Matrix for Variables

\begin{tabular}{lccccccc}
\hline & Mean & S.D. & V1 & V2 & V3 & Alpha $^{\mathrm{a}}$ & $\mathrm{CR}^{\mathrm{b}}$ \\
\hline $\begin{array}{l}\text { V1 IT maturity } \\
\begin{array}{c}\text { V2 IS/IT investment evaluation } \\
\text { methodology }\end{array}\end{array}$ & 28.52 & 6.95 & $.57^{\mathrm{c}}$ & & & .88 & .83 \\
$\begin{array}{c}\text { V3 IS/IT benefits realization } \\
\text { methodology }\end{array}$ & 13.05 & 3.14 & $.418^{* * *}$ & .68 & & .86 & .89 \\
\hline
\end{tabular}

$+\mathrm{p}<.10 ;{ }^{*} \mathrm{p}<.05 ;{ }^{* *} \mathrm{p}<.01 ; * * * \mathrm{p}<.001 ;{ }^{\mathrm{a}}$ Internal Consistency Reliability Cronbach's coefficient alpha; ${ }^{\mathrm{b}}$ Composite Reliability (Fornell and Larcker, 1981); ${ }^{\mathrm{c}}$ The diagonal (in italics) shows the average variance extracted (Fornell and Larcker, 1981) for each construct.

The reliability analysis (alpha) was conducted on these three main constructs (see Table 1). Table 1 presents the descriptive statistics and Pearson correlation for the variables used in this study. Confirmatory factor analysis was then used to construct a measurement model composed of the IT maturity, IEMs and BRMs constructs using partial least squares (PLS). All variables within the model were regarded as separate reflective measures. Churchill (1979) has suggested that convergent and discriminant validities should be examined for construct validity. Therefore, we assessed convergent validity by examining composite reliability and average variance extracted (AVE) from the measures (Hair et al., 1998). Our composite reliability values of the three constructs were between 0.83 and 0.89 . Their AVE values were between 0.57 and 0.68 and these values provided further evidence of convergent validity (Fornell and Larcker, 1981). These AVE values could also be used to assess discriminant validity (Fornell and Larcker, 1981) which was evident in the results of this study as AVE values for three constructs were higher than the largest squared pairwise correlation between three constructs (0.56) (Espinoza, 1999). In addition, the multicollinearity was not an issue as MANOVA and ANOVA were used to analyse the data. The relationship between the level of IT maturity and the use of IEM/BRM would be empirically tested by this survey later (in research findings - stage 2).

\section{RESEARCH FINDINGS}

\section{Case Study Results}

The case study results indicated that neither organization employed a formal IS/IT investment evaluation methodology (although an informal process was used) and both had problems in understanding what constituted an IS/IT investment evaluation. The 
second organization (case 2) had adopted a formal IS/IT benefit realization methodology and had fewer problems than the first organization (case 1) which had not adopted such a methodology. A number of issues emerged from the analysis of the case study data. For both cases:

no formal IS/IT investment evaluation methodology was used;

there was a lack of understanding of the evaluation approach;

an informal IS/IT investment evaluation process was used; and

there was a focus on quantitative IS/IT investment evaluation measures.

Over the course of the research three reflective phases were observed in which our understanding of the nature of investment evaluation and benefits management in relation to the levels of IT maturity was clarified. In phase 1, a basic dichotomy emerged in which the research data indicated that organizations that used a BRM could be classified as having high IT maturity and those that did not, low IT maturity. In phase 2, this idea was extended to produce an initial matrix in which stages of maturity were plotted against use or non-use of a BRM. However, there were some conceptual difficulties with this first cut and so in a third phase a more sophisticated matrix has evolved to better explain the research evidence.

\section{Phase 1}

Through analysis of the data collected via the first survey and case study, we were able to conclude that those organizations which employed a BRM were more likely to: (a) use formal processes for their investment evaluation and benefit realization activities;

(b) be more confident about what they did in their IS/IT activities; (c) have better integration of their IS/IT functions; and (d) manage their projects or contracts to achieve better results and with less problems and hence, at a higher level of IT maturity. This gave rise to Figure 2. Given the discussion previously about stages of growth and maturity, it seemed reasonable to assume that organizations with high IT maturity would be more likely to be able to implement a benefit realization methodology while low IT maturity organizations would be less likely to.

This was corroborated by the research data. The results showed that while most responding organizations had used some sort of IS/IT investment evaluation methodology, only a relatively small percentage of organizations employed a benefits realization methodology. For example, in case 2 where a formal benefits realization 
methodology had been employed, greater control over its outsourcing contracts and better IS/IT integration within the organization was experienced than case 1 which had no formal or informal benefit realization methodology. Therefore, we concluded that usage of an IS/IT investment evaluation methodology and/or IS/IT benefits realization methodology was highly likely to be associated with an organization's IT maturity. It was also concluded that organizations with higher IT maturity were more likely to adopt a formal benefits realization methodology (see Figure 2).

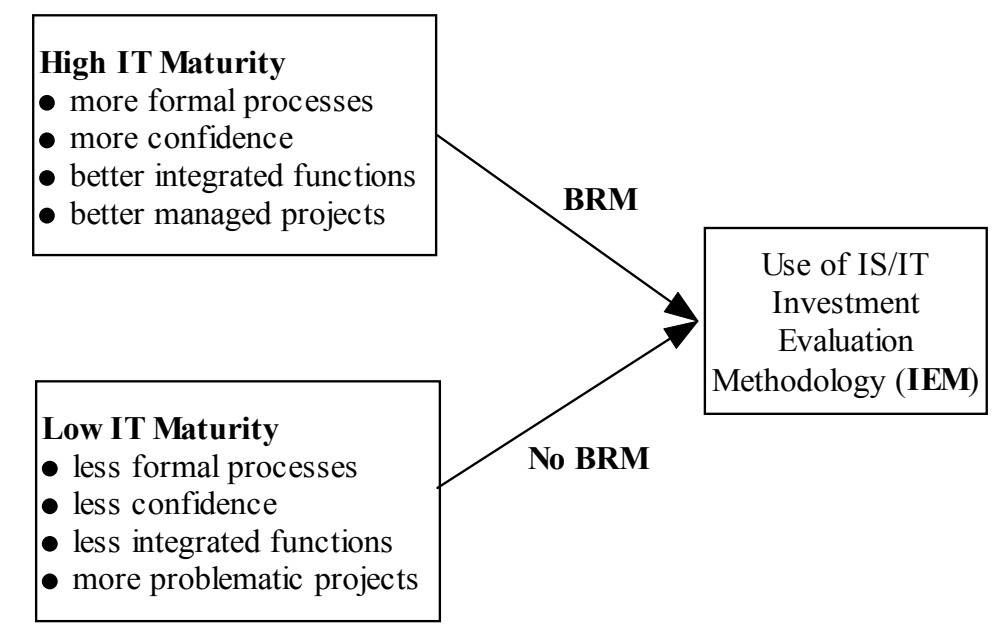

Figure 2 BRM (high IT maturity) vs. no BRM (low IT maturity)

However, such a simple dichotomy was felt to be insufficient to embrace the richness of detail that had been uncovered especially in the case studies and so a deeper analysis was performed by plotting the 7 S's in Galliers and Sutherland's model (1991) against the two case studies. Figure 3 shows that case 2 was at a higher stage than case 1. As mentioned earlier, both organizations had adopted an informal IEM. However, case 2 had adopted a BRM while case 1 did not. All of case 1's seven perspectives were mostly at stage 4 whereas case 2's seven perspectives were mostly at stage 5 . Now, while this was illuminating, it did not in itself bring into focus the direct issues of whether use of an IEM (or not) and use of a BRM (or not) were indicative of a level of maturity. We began to understand that while perspectives such as style or structure might be useful generic attributes, they did not in themselves provide a 'metric' for an organization's progress with respect to investment evaluation or benefits management. For example, we were interested in plotting whether the absence of use of a BRM indicated a particular level of (im)maturity. So a second phase of analysis began in which this was more directly 
modeled.

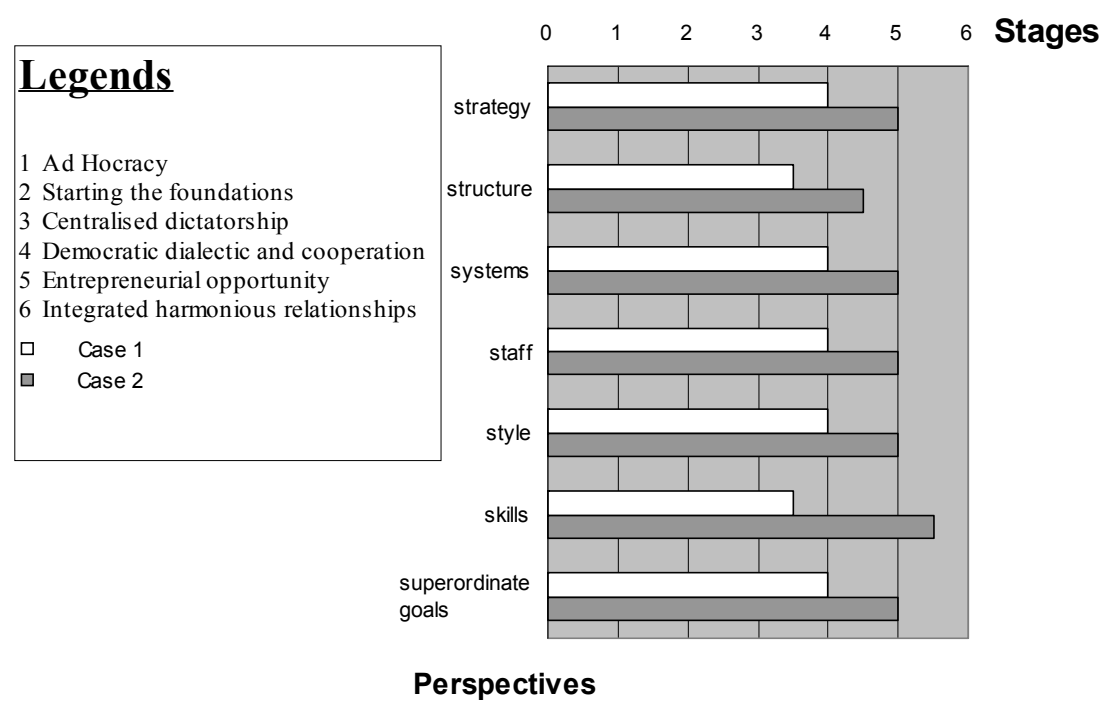

Figure 3 Growth stages for case 1 and case 2 using the Galliers \& Sutherland's Model (1991)

\section{Phase 2}

A maturity matrix was developed based on the survey 1 and case study data and after consultation between the researchers and in some cases further explanation from the interviewees. Figure 4 below is a $6 \times 2$ matrix plotting the use of a formal BRM methodology (yes or no) against maturity stages. Case 1 was located in quadrant A and it had no formal BRM with an informal IS/IT investment evaluation methodology (IEM). Similarly, case 2 was located in quadrant D with an informal IEM and a formal benefits realization methodology (BRM).

An obvious problem with the matrix is that its two dimensional nature, with axes of BRM and maturity, does not allow consideration of the use of an IEM. In other words, there are actually three dimensions in this analysis - maturity (as with the stages of Galliers and Sutherland's model), use of BRM and use of IEM. Further, it is difficult to describe D concisely. Just what is an informal/formal IEM? While this may have been an implication of choosing six stages of maturity against BRM for the matrix, it clearly required further examination. These matters were resolved in phase 3 . 


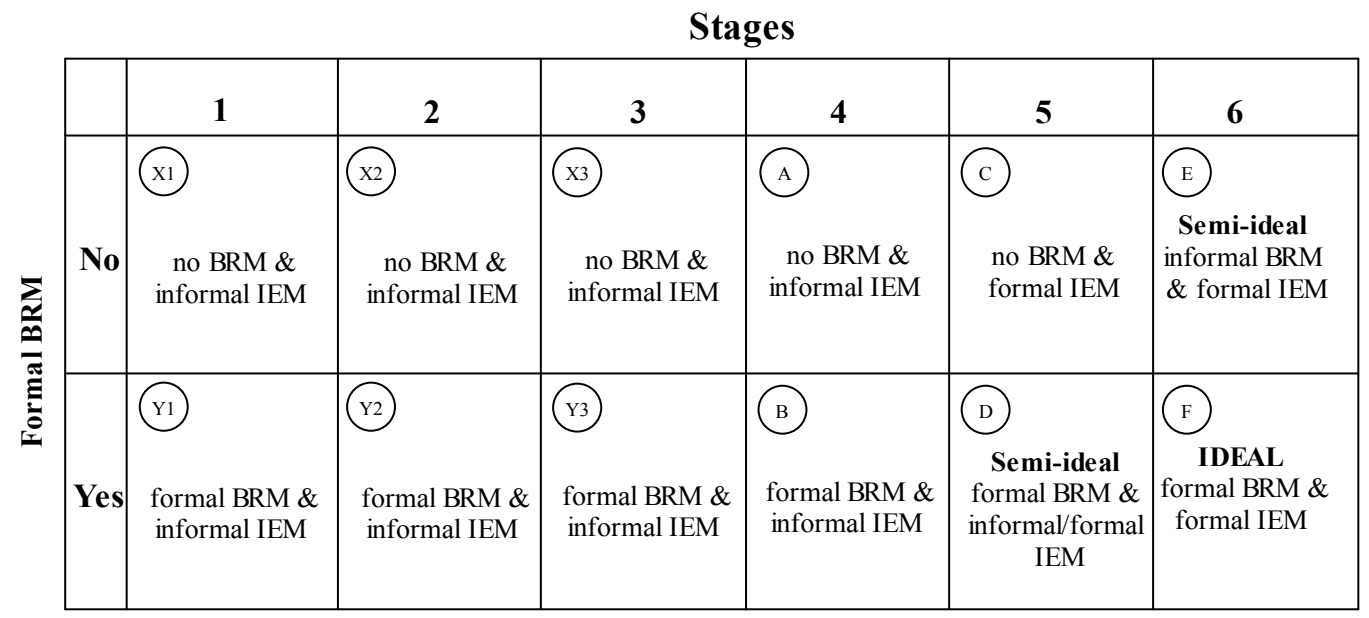

Figure 4 First cut maturity model of stages vs. formal BRM matrix

More significantly from the point of view of this conceptual development, the act of plotting where case 1 and 2 gave rise to the idea that Figure 4 could also be used as a roadmap for organizations to determine how to reach maturity. The following encapsulated that discussion.

It was observed that it would be almost impossible for an organization to reach the semi-mature quadrants ( $\mathrm{D}$ and $\mathrm{E}$ ) without having at least a formal BRM and an informal IEM or vice versa. According to Galliers \& Sutherland (1991), it is not possible for an organization to jump straight from an early stage to a very advanced stage. For example, an organization with a centralized end-user computing system at the model's Stage 3 needs to go through several stages before it can transform itself into an organization with a decentralized end-user computing system at Stage 6 (semi-ideal or ideal). Ideal refers to when the organization is fully mature and adopts both formal IEM and BRM whereas Semi-ideal refers to when the organization is almost fully mature and adopts at least one formal methodology. Organizations really have to evolve through stages progressively, even if the transition is very brief. Organizations also need time to train the stakeholders (i.e. about the processes of IS/IT investment evaluation and benefit realization) and manage the required change before they can go to the next stage.

When an organization is in the early stages, the organization is unlikely to have implemented a formal BRM or a formal IEM. Organizations at an early stage generally are not ready to implement formal BRMs or IEMs as they don't normally possess 
knowledge about formal IS/IT investment evaluation and benefits realization concepts and practices. However, it is arguable that large organizations would be able to implement a simple informal IEM (e.g. NPV and ROI) in early stages. Therefore, it is possible to merge the first 4 stages since there is no difference in terms of adopting IEMs and BRMs in these early stages (see Figure 5). This matrix will be tested and validated in the second survey conducted later.

\section{Stages of IT Maturity}

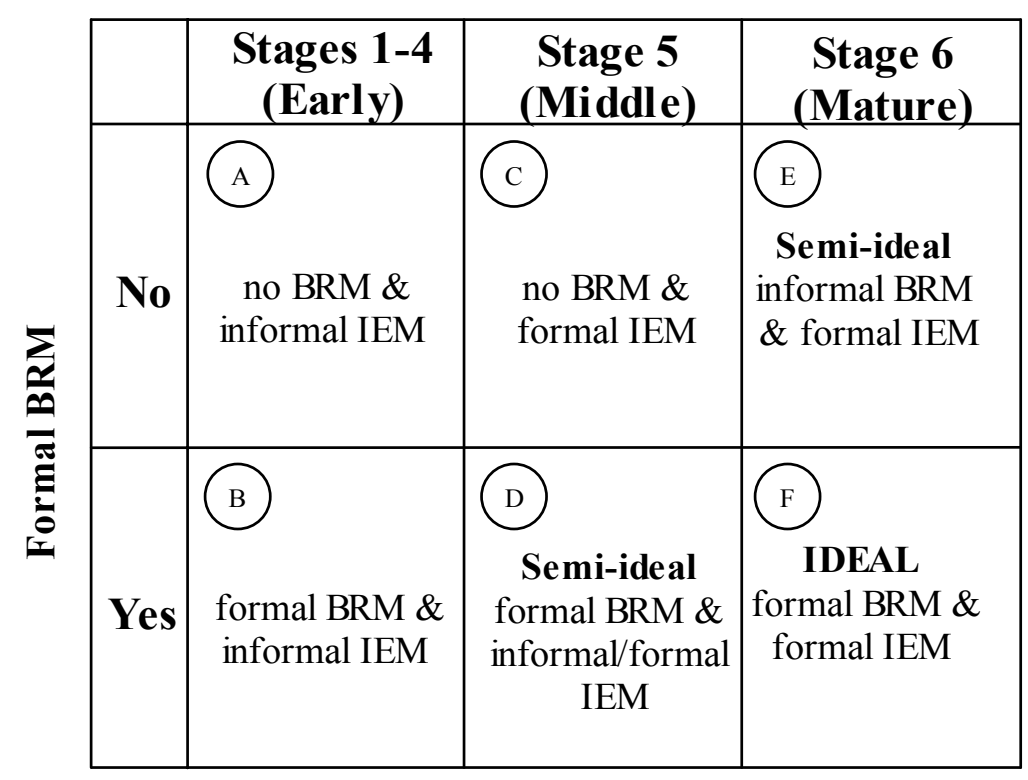

Figure 5 A revised maturity model of stages vs. formal BRM matrix

Note that it was considered unlikely for an organization to go from B back to A, quadrant $\mathrm{D}$ back to $\mathrm{C}$, or $\mathrm{F}$ back to $\mathrm{E}$. This was because once an organization has adopted a BRM (or an IEM), it would be typically difficult to undo the methodology and "forget" about the benefit realization concepts and/or investment evaluation practices. It would simply be too costly for an organization to go back to the previous stages, although this is always possible in a culture of cutbacks and 'leaner and meaner' strategies driven by consultants within some organizations. For any organization, arguably the ultimate goal is to go to $\mathrm{F}$ - the mature stage, with both formal BRM and formal IEM. Organizations which reside in $\mathrm{D}$ in the middle stage and $\mathrm{E}$ in mature stage are arguably not yet fully mature. Organizations under these two quadrants will have not yet adopted both formal IEM and formal BRM together. It was considered logical that an organization should 
adopt a formal IEM before a formal BRM, given the earlier discussion about the connection between IEM and BRM in a previous section. Alternatively, an organization could adopt both methodologies at the same time although it may be unrealistic as adopting a formal methodology usually requires substantial investment in time and money.
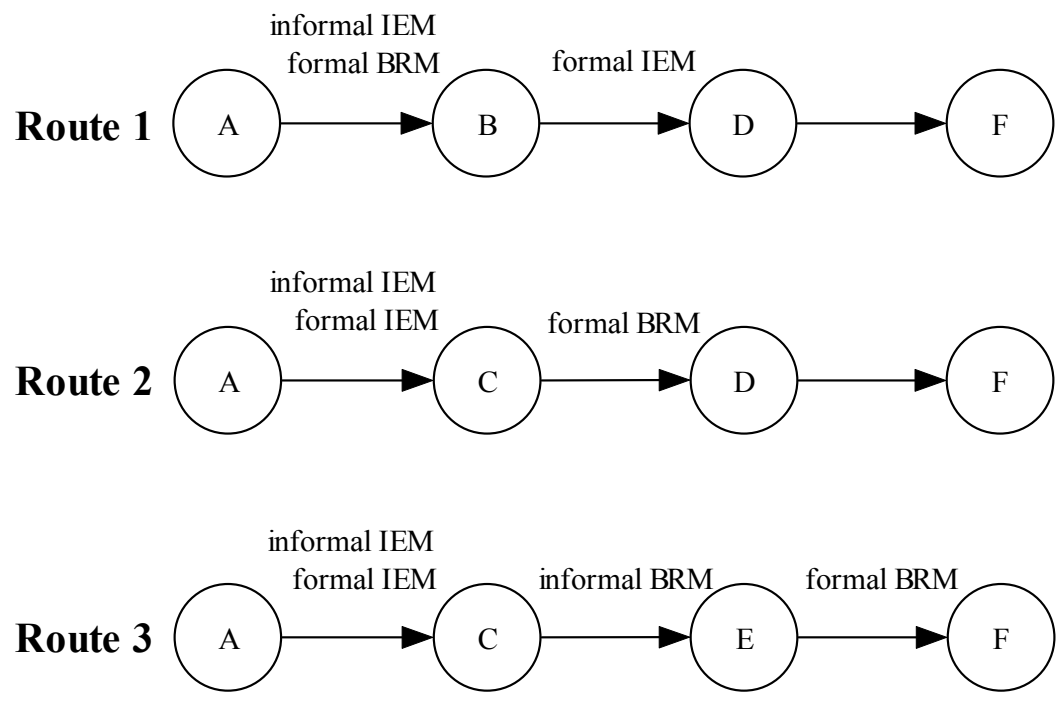

Figure 6 Three routes to the mature stage

Three routes were identified as being sensible rational routes for organizations to follow. Case 2 was at D and seemed to have taken the first route in Figure 6. The organization had taken a relatively long time in transitioning from A to B. However, once the BRM was implemented successfully case 2 seemed to have evolved quickly and arrived at $\mathrm{D}$ in a relatively short amount of time. The next step for the organization would be to adopt a formal IEM and move towards F, the mature stage. On the other hand, case 1 was at A. From here, it can take routes 1, 2, or 3 to get to $F$, the mature stage. Depending on the levels of IT maturity of the organizations, routes 2 and 3 are preferable to route 1 as organizations can then adopt a formal IEM before a formal BRM. Also, route 2 is preferable to route 3 because a formal BRM is adopted earlier in route 2 because it will enable organizations to mature sooner and thus progress more quickly to F. Therefore, the order of the preference for the three possible routes is: Route 2, Route 3, and Route 1. 


\section{Phase 3}

The main purpose and focus of phase three was to accommodate and rationalize concerns about the description of informal IEM and more generally how well Figure 5 fitted the research data. Evidence gathered from the research data indicated that for investment evaluation, three possibilities existed - no IEM, informal IEM and formal IEM. However, given that we had developed a revised maturity model in which there were three stages this did not provide a neat fit. In the case study research, a description of informal IEM had been defined as where some form of investment appraisal was being undertaken but not using a recognized proprietary methodology such as Balanced Scorecard. However, in terms of maturity, one could still make a strong case that socalled informal IEMs that attempt to link investment decisions to strategic priorities are qualitatively more mature than those that only quantify the net return in financial terms. Such approaches, while not proprietary would still be mature. And so, quite sensibly, four possible situations for IEMs emerged and are defined as follows:

No IEM: This is unlikely for large organizations;

Traditional IEM, where financial indicators such as NPV or ROI are used as the only basis for selection;

Advanced IEM, where although financial indicators such as NPV or ROI are used, decisions are in addition made on further strategic grounds; and

Formal IEM where advanced proprietary methodologies are employed.

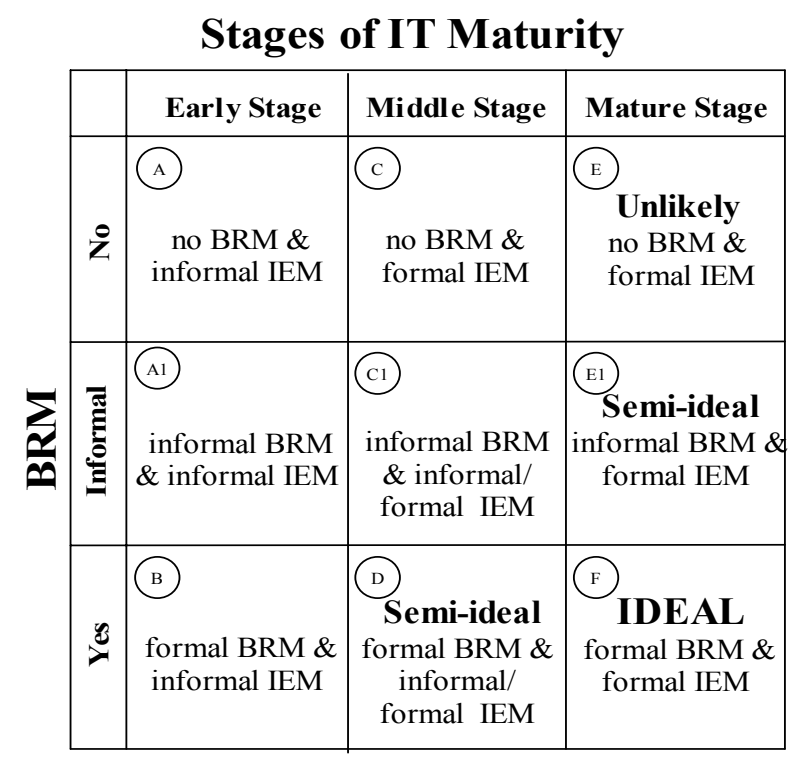

Figure 7 Final IS/IT maturity, investment evaluation and benefit realization methodologies matrix 
Having accepted the principle that IEMs may have some degree of informality begs the same question with respect to BRMs. So far, our analysis had only considered that an organization may either not have a formal BRM or follow a proprietary BRM methodology. It would be reasonable to entertain situations where an organization would be mature enough to recognize a need to have a BRM yet not be aware of or choose not to adopt a proprietary BRM? Perhaps this would be especially likely if the organization had previously adopted an advanced or formal IEM. So this led to an acceptance of three situations for BRMs: (1) no BRM; (2) informal BRM; and (3) formal BRM. In view of the relative immaturity of BRMs compared to IEMs it was felt that three situations were sufficiently rich for our purposes here. For the purpose of this study, formal IEMs and BRMs adoption refers to as the use of the well-recognized/documented advanced proprietary IS/IT investment evaluation and benefits methodologies whereas informal IEMs and BRMs adoption concerns with the use of some less documented guidelines or processes to evaluate and realize benefits from IS/IT investments. These are incorporated in the final maturity model, shown in Figure 7. There are now more routes that an organization can take to help it to reach the mature stage. However, situation in which there was a formal IEM but no BRM (quadrant E) was considered very unlikely to occur since there would be a synergy and awareness in one area that would spawn recognition in another. While the final matrix contain more permutations of routes to maturity the logic detailed earlier such as moving one step at a time between cells would still apply. The next stage is to empirically validate the final maturity matrix via the second survey.

\section{Survey Results}

Most of the respondents were IS/IT managers (36\%), CIO (25\%), IS/IT directors (15\%), and Senior Systems Coordinators (13\%). Many respondents were from service sectors in wholesale and retail (24\%), public utilities (19\%), health and pharmaceutical services (14\%), IT and communication services (9\%), and finance and banking (8\%). These respondents were typically large in revenue and number of employees by Australian standards. More than half of the responding organizations (53\%) had an IT budget of more than A $\$ 5$ million. The ANOVA not only revealed that annual turnover did significantly vary with firm size in terms of employee numbers $(\mathrm{p}<0.001)$, but also found significant differences between annual turnover and the IT budget $(p<0.001)$. This indicates that organizations with larger annual turnover and employees generally could 
afford to spend more on IS/IT projects.

The results also indicated a reasonably high adoption of IS/IT investment evaluation methodology $(64.6 \%)$ while the adoption rate for IS/IT benefit realization methodology was $42.5 \%$. The level of IT maturity also had a significant and positive correlation with the use of IS/IT investment evaluation methodology $(\mathrm{r}=0.418, \mathrm{p}<0.001)$ and the use of IS/IT benefit realization methodology $(r=0.440, \mathrm{p}<0.001)$ in Figure 7 (see Table 1). In order to validate the relationship between the level of IT maturity and the use of IEM/BRM (see Figure 7), scores from the seven elements within the Galliers and Sutherland's revised stages of growth model (1991) were divided according to the three stages (stages 1-4 (0-28 points) as the early stage, stage 5 (29-35 points) as the middle stage, and stage 6 (36-42 points) as the mature stage) as shown in Table 2.

Table 2 Frequency of Revised Stages of IS/IT Maturity

\begin{tabular}{cccc}
\hline Stages & Accumulated points on seven elements & Numbers & Percentage \\
\hline Early Stage & $0 \sim 28$ points & 70 & $50 \%$ \\
Middle Stage & $29 \sim 35$ points & 47 & $33 \%$ \\
Mature Stage & $36 \sim 42$ points & 24 & $17 \%$ \\
\hline
\end{tabular}

The hypotheses were tested by MANOVA analysis and then one-way ANOVA. The IEMs and BRMs as dependent variables were analysed using MANOVA by three stages of IS/IT maturity as the independent categorical variable (as listed in Table 3). Box's M test was nonsignificant at $\mathrm{p}=0.070(\mathrm{~F}=11.996)$ and this indicated equality of the variance/covariance matrices of the multiple dependent variables across treatment groups. Significant differences were found among four cells on all variables (Wilks' Lambda $\mathrm{F}=$ 6.119; p-value = 0.000). An ANOVA was then conducted on each variable and all were statistically significant. Follow-up comparisons were made using Fisher's leastsignificant-difference (LSD) test.

According to the ANOVA results (see Table 3), there were significant differences in the use of IEMs between three stages, indicating that there was a positive relationship between the level of IT maturity and the use of IEM. This also showed that the IT maturity had played a significant role in dictating the use of IEMs. In addition, there were also significant differences in the use of BRMs between three stages, indicating that there was a positive relationship between the level of IT maturity and the use of BRM. This also showed that the IT maturity had played a significant role in dictating the use of BRMs. 
Table 3 Influence of IS/IT maturity on IEMs and BRMs using One-way ANOVA

\begin{tabular}{|c|c|c|c|c|c|}
\hline $\begin{array}{l}\text { Dependent } \\
\text { Measures }\end{array}$ & $\begin{array}{l}\text { Early Stage } \\
(\mathbf{n}=70)\end{array}$ & $\begin{array}{l}\text { Middle Stage } \\
(\mathrm{n}=47)\end{array}$ & $\begin{array}{l}\text { Mature Stage } \\
(\mathrm{n}=24)\end{array}$ & $\begin{array}{l}\text { Overall Test } \\
\text { Results } \\
\mathrm{F}_{(\mathrm{df}=2,138)} \\
\text { p-Value }\end{array}$ & $\begin{array}{l}\text { Fisher's Least-significant- } \\
\text { difference (LSD) Test: } \\
\text { Significantly Different } \\
\text { Pairs }(\alpha=0.05)\end{array}$ \\
\hline IEMs & $\begin{array}{l}\text { Mean } 12.10 \\
\text { SD } 3.18\end{array}$ & $\begin{array}{l}\text { Mean } 13.55 \\
\text { SD } 2.84\end{array}$ & $\begin{array}{l}\text { Mean } 14.83 \\
\text { SD } 2.63\end{array}$ & $\begin{array}{l}8.498 \\
p=0.000\end{array}$ & $\begin{array}{l}\text { Mature }>\text { Middle } \\
\text { Mature }>\text { Early } \\
\text { Middle }>\text { Early }\end{array}$ \\
\hline BRMs & $\begin{array}{l}\text { Mean } 10.40 \\
\text { SD } 3.21\end{array}$ & $\begin{array}{l}\text { Mean } 12.06 \\
\text { SD } 2.98\end{array}$ & $\begin{array}{l}\text { Mean } 13.88 \\
\text { SD } 2.76\end{array}$ & $\begin{array}{l}12.533 \\
p=0.000\end{array}$ & $\begin{array}{l}\text { Mature }>\text { Middle } \\
\text { Mature }>\text { Early } \\
\text { Middle }>\text { Early }\end{array}$ \\
\hline
\end{tabular}

Significant level is less than 0.10 .

\section{IMPLICATIONS AND CONCLUSION}

A maturity model was developed after the analysis of the case study data and was empirically validated via a subsequent survey in Australia. It was shown that IS/IT investments in many organizations are huge and are increasing rapidly every year, yet there is still a lack of understanding of the impact of the proper IS/IT investment evaluation processes and practices in these organizations. At the same time, the issue of expected and actual benefits realized from IS/IT investments has also generated a significant amount of debate in the IS/IT literature amongst the researchers and practitioners. The paths to IT maturity and the maturity model have tried to fill an important gap by suggesting to senior managers when and how the IS/IT investment evaluation and benefits realization methodologies could be adopted. A key contribution of this research is to provide large Australian organizations with guidelines which relate to when, in terms of the organization's maturity, it will be possible in practice to meaningfully deploy benefit realization and financial evaluation. These pathways to IT maturity reveal when such deployment will begin to assist the organization to learn and further mature.

As stated earlier, many Australian organizations have encountered difficulties in their IS/IT investment evaluation practices and many of these problems have been identified by researchers and academics (e.g. Lin et al., 2005; Love et al. (2005)). The existence of a roadmap reinforces the need for organizations to more explicitly plan their intentions and think about their paths to maturity thus ensuring that an appropriate evaluation methodology is implemented in order to overcome or minimize problems that have been or may be encountered. For example, an immature organization can apply the 
Galliers \& Sutherland's Model (1991) to determine its stage of growth (IS/IT maturity) and then implement a relevant route in the matrix which incorporates the use of formal IS/IT investment evaluation (IEM) and benefit realization (BRM) methodologies. The benefits of using such methodologies enable Australian organizations to reduce the extent of concealment and overstatement of costs of IS/IT investments and in identifying and assessing the qualitative costs and benefits of their IS/IT investments.

The paths to IT maturity and the maturity model may force senior management in large Australian organizations to rethink their understanding and use of the benefit realization and IS/IT investment evaluation practices. As indicated by the results from the survey and two case studies, the majority of participants did not know much about the IS/IT investment evaluation and benefit realization concepts and practices. Many of them even thought that some outdated techniques (such as budgetary process) or mainly quantitative techniques (such as NPV) constituted a formal IS/IT investment evaluation methodology. Only a small minority of the survey respondents had implemented a benefit realization methodology.

Furthermore, the paths to IT maturity and IS/IT maturity, investment evaluation and benefit realization methodologies matrix are devised to alert senior management that both the IS/IT investment evaluation and benefit realization practices are important for the success of the organization's systems development process. The IS/IT investment evaluation methodology improves the decision-making process for IS/IT investments while the benefit realization methodology ensures that the benefits claimed for those investments are realized. The matrix developed is more about showing the options for maturity (using IEM and BRM use as its means of measurement) than about the right way to do IEM and BRM. Finally, used in conjunction with the Galliers \& Sutherland's Model (1991), the paths to IT maturity and the maturity model can not only clarify the location of the organization in IS/IT maturity terms, but also provide insights into how and when the formal benefit realization and IS/IT investment evaluation methodologies should be used.

\section{REFERENCES}

Changchit, C., Joshi, K.D., and Lederer, A.L. (1998). Process and Reality in Information Systems Benefit Analysis. Information Systems Journal, 8, 145-162.

Churchill, G. A. (1979), A Paradigm for Developing Better Measures of Marketing Constructs, Journal of Marketing Research, 16, 64-73. 
Dibb, S. (2001). Customer Relationship Management and Barriers to the One Segment. Journal of Financial Services Marketing, 6(1), 10-23.

Dos Santos, B.L. (1994). Assessing the Value of Strategic Information Technology Investments, In L. Willcocks (Ed.), Information Management: The Evaluation of Information Systems Investments, (Ch7, 133-148). Chapman \& Hall, London.

Eisenhardt, K. M. (1989). Building Theories From Case Study Research, Academy of Management Review, 14(4), 532-550.

Espinoza, M. M. (1999) Assessing the Cross-Cultural Applicability of a Service Quality

Measure: A Comparative Study between Quebec and Peru, International Journal of Service Industry Management, 10(5), 449-468.

Farbey, B., Land, F. and Targett, D. (1992). Evaluating Investments in IT, Journal of Information Technology, 7, 109-122.

Fornell, C., and D. F. Larcker (1981). Evaluating Structural Equation Models with Unobservable Variables and Measurement Error, Journal of Marketing Research, 18(1), 39-50.

Galliers, R. D. and Sutherland, A. R. (1991). Information Systems Management and Strategy Formulation: The 'Stages of Growth' Model Revisited, Journal of Information Systems, 1, 89-114.

Hair, J. F., Anderson, R. E., Tatham, R. L., and Black, W. C. (1998) Multivariate Data Analysis (5th ed.), Prentice Hall, Englewood Cliffs, NJ.

Laitinen, E. K. (2002) A Dynamic Performance Measurement System: Evidence from Small Finnish Technology Companies, Scandinavian Journal of Management, 18, 65-99.

Lee, B. and Barua, A. (1999). An Integrated Assessment of Productivity and Efficiency Impacts of Information Technology Investments: Old Data, New Analysis and Evidence, Journal of Productivity Analysis, 121, 21-43.

Lin, K., Lin, C. and Tsao, H. (2005) IS/IT Investment Evaluation and Benefit Realization Practices in Taiwanese SMEs, Journal of Information Science and Technology, 2(4), 44-71

Love, P.E.D., Irani, Z., Standing, C., Lin, C., and Burn, J. (2005). The Enigma of Evaluation: Benefits, Costs and Risks of IT in Small-Medium Sized Enterprises, Information and Management, 42(7), 947-964.

Miles, M.B. and Huberman, A.M. (1994). Qualitative Data Analysis: An Expanded Sourcebook, Sage Publications, California. 
Mingers, J. (2001). Combining IS Research Methods: Towards a Pluralist Methodology. Information Systems Research, 12(3), 240-259.

Mohamed, E. K. A. and Hussain, M. M. (2005). Management accounting and performance measurement practices in service sector in Oman, International Journal of Management and Decision Making, 6(2), 101.

Nolan, R. L. (1979). Managing the Crises in Data Processing, Harvard Business Review, March-April, 115-126.

Nunnally, J. C. (1978) Psychometric Theory. New York: McGraw-Hill.

Parker, M. M., Benson, R. J. and Trainor, H. E. (1988). Information Economics: Linking Business Performance to Information Technology. New Jersey, Prentice-Hall.

Schultz, J. R. (2006). Measuring Service Industry Performance: Some Basic Concepts, Performance Improvement. 45(4), 13-19.

Strassmann, P. A. (1997). Will Big Spending on Computers Guarantee Profitability? Datamation, 432, February.

Takatsu, S. (1984) Reconsideration of the Present Value Method, European Journal of Operational Research, 182, 230-245.

Truax, J. (1997). Investing With Benefits In Mind: Curing Investment Myopia, The DMR White Paper, 1-6.

Tsao, H., Lin, K. H., and Lin, C. (2004) An Investigation of Critical Success Factors in the Adoption of B2BEC by Taiwanese Companies, The Journal of American Academy of Business, Cambridge, 5(1/2), 98-202.

Wang, E. T. G. (2002) Transaction Attributes and Software Outsourcing Success: An Empirical Investigation of Transaction Cost Theory, Information Systems Journal, $12,153-181$.

Ward, J., Taylor, P. and Bond, P. (1996). Evaluation and Realization of IS/IT Benefits: An Empirical Study of Current Practice, European Journal of Information Systems, 4, 214-225.

Willcocks, L. and Lester, S. (1997). Assessing IT Productivity: Any Way Out of the Labyrinth?, in Managing IT as a Strategic Resource, Leslie Willcocks, D.F. Feeny, \& G. Islei Eds, Chapter 4, The McGraw-Hill Company, London, 64-93.

WITSA (2004). Digital Planet 2004: The Global Information Economy, World Information Technology and Services Alliance, Global Insight, Inc, Source: [OnLine] http://www.witsa.org/.

Yin, R. K. (2002). Case Study Research, Design and Methods, 3rd Ed., Newbury Park, 
Contemporary Management Research 194

Sage Publications. 